\title{
$\mathrm{PH} \mathbf{8 8}$
}

\section{Delimitando el Condado: trascendencia de la vitivinicultura}

Juan José Raposo González | arquitecto, Universidad de Sevilla

URL de la contribución <www.iaph.es/revistaph/index.php/revistaph/article/view/3650>

\section{RESUMEN}

Desde tiempos inmemoriales, la vitivinicultura ha estado presente en las tierras del Condado. El cultivo de la vid para la elaboración de vino ha ocupado a esta población durante milenios, forjando un especial vínculo con su territorio. Se trata de una cultura generada a partir del entendimiento y sabio aprovechamiento de los recursos naturales; una práctica tradicional que surge de la unión entre los elementos humanos y naturales propios del Condado.

Este Condado presenta dificultades para su delimitación y ha sido generalmente considerado dentro de las "tierras llanas" de Huelva, consagradas históricamente a los cultivos de cereal, viñedo y olivar. Sin embargo, este estudio enfatiza la antigua tradición de la vid por su repercusión sobre los aspectos culturales y territoriales comunes en estos pueblos. Se propone una lectura de este lugar diverso desde el punto de vista de la vitivinicultura, subrayando la importancia de esta histórica práctica, mantenida hasta la actualidad, en la conformación de su paisaje y en la generación de su patrimonio.

La vitivinicultura como elemento vivo aporta cohesión al territorio heterogéneo del Condado y permite su reconocimiento, claro y diferenciado, como un sistema cultural único. El ancestral desempeño de esta actividad agrícola en el Condado la ha convertido en signo fundamental de identidad para su pueblo, formando parte de la vida y el patrimonio de esta sociedad.

\section{Palabras clave}

Agricultura | Condado de Huelva| Huelva (Provincia) | Paisaje cultural | Paisaje rural | Patrimonio agrario | Vid | Vinicultura | Vino | Viticultura | Vitivinicultura | 


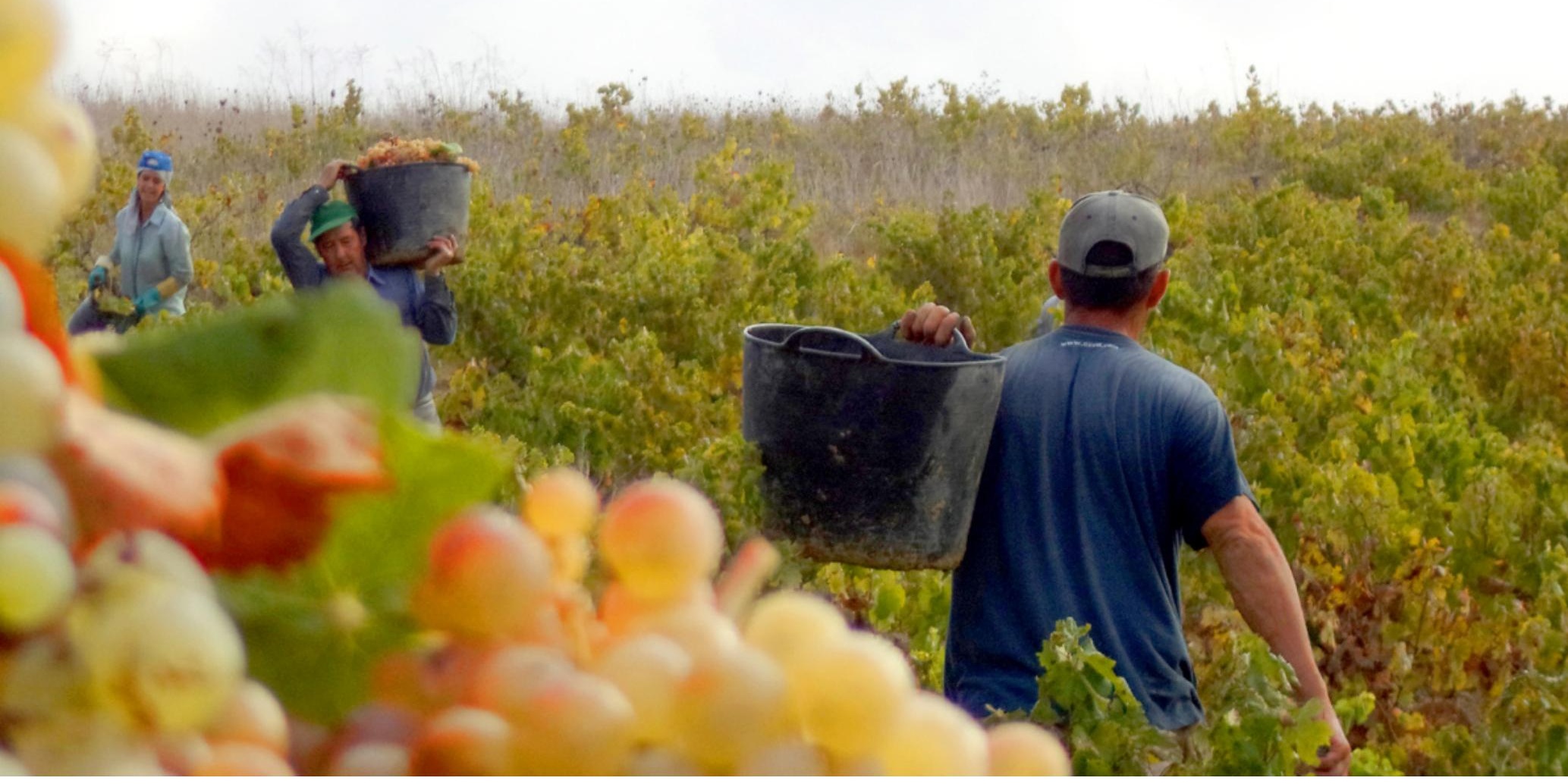

Comunidad y cooperativismo entre los vendimiadores mientras acarrean la uva hasta el remolque. Bollullos Par del Condado | foto Juan José Raposo González, autor de todas las imágenes que ilustran este artículo 
1

El documento que aquí se presenta forma parte de la investigación desarrollada en estudios de doctorado (E.T.S. de Arquitectura de Sevilla), bajo la tutela de María Teresa Pérez Cano, José Manuel Aladro Prieto y Celia Martínez Yáñez.

\section{2}

Las comarcas actuales de la provincia de Huelva son: el Andévalo, el Condado, Costa Occidental, Cuenca Minera, Huelva y Sierra de Huelva. Aunque según los parámetros agrarios, que es lo que nos ocupa, la Caracterización de Comarcas Agrarias (CONSEJERÍA DE AGRICULTURA, PESCA Y DESARROLLO RURAL, 2001) diferencia entre: Entorno de Doñana, Sierra Oriental, Sierra Occidental, Costa Occidental, Condado de Huelva, Andévalo Occidental y Andévalo Oriental.

\section{3}

Los yacimientos arqueológicos más antiguos repartidos por la región cercana a Bollullos se remontan a esta época. Se trata generalmente de restos de armas para la caza usada por pobladores nómadas (BIEDMA PÉREZ; CARRASCO TERRIZA; CLEMENTE MARTÍN et ál., 2003: 33-35)

4

El lago Ligustinus se originó en el Cuaternario, como una de las sucesivas etapas de anegamiento del original Estrecho Bético. Éste comunicaba inicialmente el Atlántico con e Mediterráneo, siendo colmatado progresivamente mediante sedimentos hasta constituir el actual valle del Guadalquivir. En su desembocadura, este lago fue el último vestigio marino del proceso, transformándose en las actuales marismas de Doñana (HERNÁNDEZ PACHECO, 1961: 107-112).

\section{5}

Un completo estudio sobre el antiguo Reino de Niebla y su proceso de transformación en Condado puede encontrarse en el trabajo de Ladero Quesada (1992).
La zona ${ }^{1}$ comúnmente reconocida por este término engloba una serie de municipios de la provincia de Huelva ${ }^{2}$ con cierta heterogeneidad tanto en su historia como en su medio físico. No obstante, a pesar de esta falta de unidad, ha perdurado hasta nuestros días bajo un sentimiento conjunto de identidad entre sus pueblos, más que como delimitación administrativa.

\section{EL CONDADO HISTÓRICO}

Su denominación hace referencia al Condado de Niebla, que es el histórico y único que existiera desde su fundación en el siglo XIV, si bien la posterior designación de Huelva como capital provincial y la creación de la propia Denominación de Origen ayudarían a extender un erróneo término de "Condado de Huelva" que ha llegado hasta la actualidad. En su origen, se trata de un amplio territorio ocupado desde hace milenios por diferentes culturas que, de manera sucesiva, han sabido explotar los recursos agrarios que el medio ofrecía. De este modo fueron surgiendo desde el Paleolítico ${ }^{3}$ asentamientos en torno a sus fértiles tierras, que eran regadas por frecuentes arroyos y riachuelos. Se genera así una ocupación diseminada de este territorio que, en cierta forma, ha perdurado hasta nuestros días, como se refleja en la compacta red de municipios cercanos del actual Condado. La proximidad del mar, acrecentada por el antiguo lago Ligustinus ${ }^{4}$ ocupando las marismas del actual Doñana, permitía aparte de la caza en estos terrenos, una variada pesca y explotaciones de salazón. Los numerosos yacimientos romanos desde el siglo II al $\mathrm{V}$ d. de C. (CASTAÑO CORRAL; MATEOS MATEOS; RIVERA SILVA, 2010: 17-19) repartidos por la comarca nos hablan de estos primeros asentamientos estables dentro de lo que podríamos denominar como "corona de terrenos fértiles" en torno a la antigua costa y que configura hoy el Condado.

Con la ocupación musulmana se inicia verdaderamente un sistema administrativo para la región, que se conservará parcialmente durante la reconquista, pues el reino musulmán de Niebla ${ }^{5}$ abarcaría más allá de la actual provincia de Huelva (ROLDÁN CASTRO, 1993: 161-178). De modo que en 1262 las tierras arrebatadas por Alfonso X el Sabio a Ibn Mahfuz de Niebla son incorporadas al Reino de Sevilla. Continuando una política repobladora de estos territorios, sería en 1368 cuando se inicia la etapa señorial con Juan Alonso Pérez de Guzmán y Osorio, nombrado I Conde de Niebla como recompensa por su defensa de Tarifa (LAREDO QUESADA, 1992: 6162). Ciertamente la delimitación de este condado histórico fundacional era algo más reducida, comprendiendo "la villa de Niebla y todas las tierras que de ella dependían: Trigueros, Beas, Rociana, Villarrasa, Bonares, el castillo de Alhajar y el Andévalo, la fortaleza de Juan Pérez, Calañas, Facanias (Valverde del Camino), El Portichuelo y Paimogo" (AMADOR DE LOS RÍOS Y FERNÁNDEZ DE VILLALTA, 1891: 162-164). 

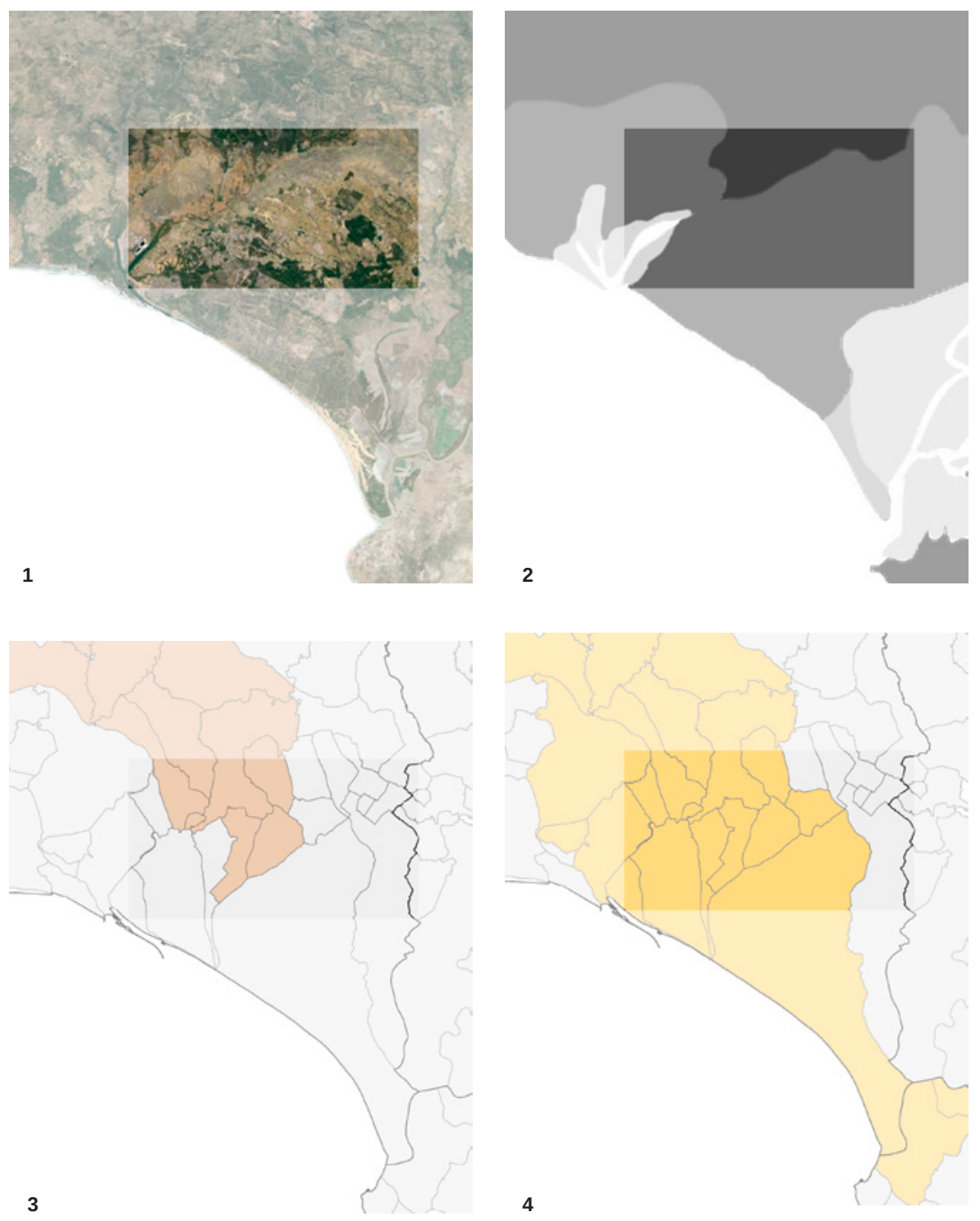

4
1. Foto aérea del territorio del Condado. Se aprecia la diferenciación con las zonas inmediatas

2. Fases geológicas de conformación del Condado. El ámbito marcado se corresponde con depósitos limoarenosos

3. Municipios que pertenecieron al histórico Condado de Niebla (rosa)

4. Municipios que quedaron integrados dentro del Ducado de Medina Sidonia (amarillo)

Lo que hoy se entiende por comarca del Condado tampoco se delimitaría con la ampliación que el Señorío de Sanlúcar de Barrameda, posteriormente Ducado de Medina-Sidonia, realizara en el siglo XV para conectar con sus terrenos gaditanos, y que además de los ya mencionados municipios, englobaría a: Bollullos Par del Condado, La Palma del Condado, Villalba del Alcor, Manzanilla, Chucena, Hinojos, Almonte, Lucena del Puerto, San Juan del Puerto, Moguer y Palos de la Frontera. Estos lugares, a pesar de que no formaron parte de dicho Condado fundacional, sí quedarán integrados a partir de entonces dentro del mencionado Ducado, que entre otros títulos nobiliarios incluía el Condado de Niebla. 


\section{EL CONDADO FísICO}

6

El Condado completo englobaría diferentes territorios físicos: desde la costa, las marismas y los pinares de Doñana, pasando por la zona de cultivos y dehesas, hasta finalmente la zona de baldíos y vegetación silvestre en e contacto con la Sierra.

7

Es muy destacable, para el correcto entendimiento del lugar, la concordancia exacta entre las condiciones naturales apropiadas para la vid y el territorio ocupado por estos pueblos del Condado para generar su cultura propia.

8

Las tierras calizas se consideran apropiadas para la obtención de vinos con cuerpo y aptos para la crianza (el método tradicional del Condado). Generalmente, sobre suelos pobres o inadecuados para otros cultivos, la vid produce excelentes vinos.
El territorio que conforma el Condado presenta un variado medio físico con unas características particulares para cada zona ${ }^{6}$. De entre todas las presentes, quizás la más significativa por su representatividad sea la marcada por los viñedos, que aporta cierta homogeneidad y unidad al conjunto comarcal. Este cultivo, que ha estado presente en menor o mayor medida en todos sus municipios, requiere unas condiciones naturales especiales que ayudan a acotar aún más el ámbito de estudio de lo que sería propiamente el Condado del vino y de la vid?.

Los límites naturales que definen genéricamente el Condado se vuelven imprecisos cuando lo que se quiere delimitar es la vitivinicultura característica de este territorio. Por ello, el límite sur del Atlántico retrocede hasta el espacio natural de Doñana y su entorno; así como el correspondiente al norte avanza desde el comienzo del Andévalo, con espesa cobertura vegetal, hasta las tierras de labor del Condado, continuación del cerealero Campo de Tejada; siendo los límites este-oeste algo más difusos, pues el cultivo de la vid va desapareciendo progresivamente hacia los extremos del Condado, representados por el río Odiel y las marismas del Guadalquivir respectivamente.

La acotación de esta comarca según el estudio pormenorizado del cultivo permite una lectura clara del resto de variantes físicas que son fundamentales para el desarrollo del viñedo en este lugar. La propia geomorfología caracteriza el terreno, conformado mediante sedimentos marinos y fluviales que fueron progresivamente colmatando el primitivo estuario del Guadalquivir. El suelo más antiguo, el escudo terciario perimetral de su desembocadura, corresponde a la actual banda de tierras de labor del Condado, y a partir de ésta aparecen los suelos posteriores -depósitos limoarenosos del Plioceno, en el Terciario- (CASTAÑO CORRAL; MATEOS MATEOS; RIVERA SILVA, 2010: 29) coincidentes con los suelos destinados a la viña. En términos de litología, se trata principalmente de suelos denominados, según la Consejería de Medio Ambiente (MAPA, 2005), como "regosoles calcáreos y cambisoles cálcicos con litosoles, fluvisoles calcáreos y rensinas"8.

La topografía del Condado también manifiesta claramente estos procesos de formación, apreciándose una zona de suave pendiente que se diferencia de la planicie del actual Parque Nacional, conformada posteriormente en el Cuaternario por arenas marinas y eólicas.

Se trata en suma de un relieve que desciende levemente hacia la costa y que apenas supera los 100-150 m de altitud máxima, constituyendo una franja longitudinal elevada coincidente con la zona propia de viñedos del Condado. 

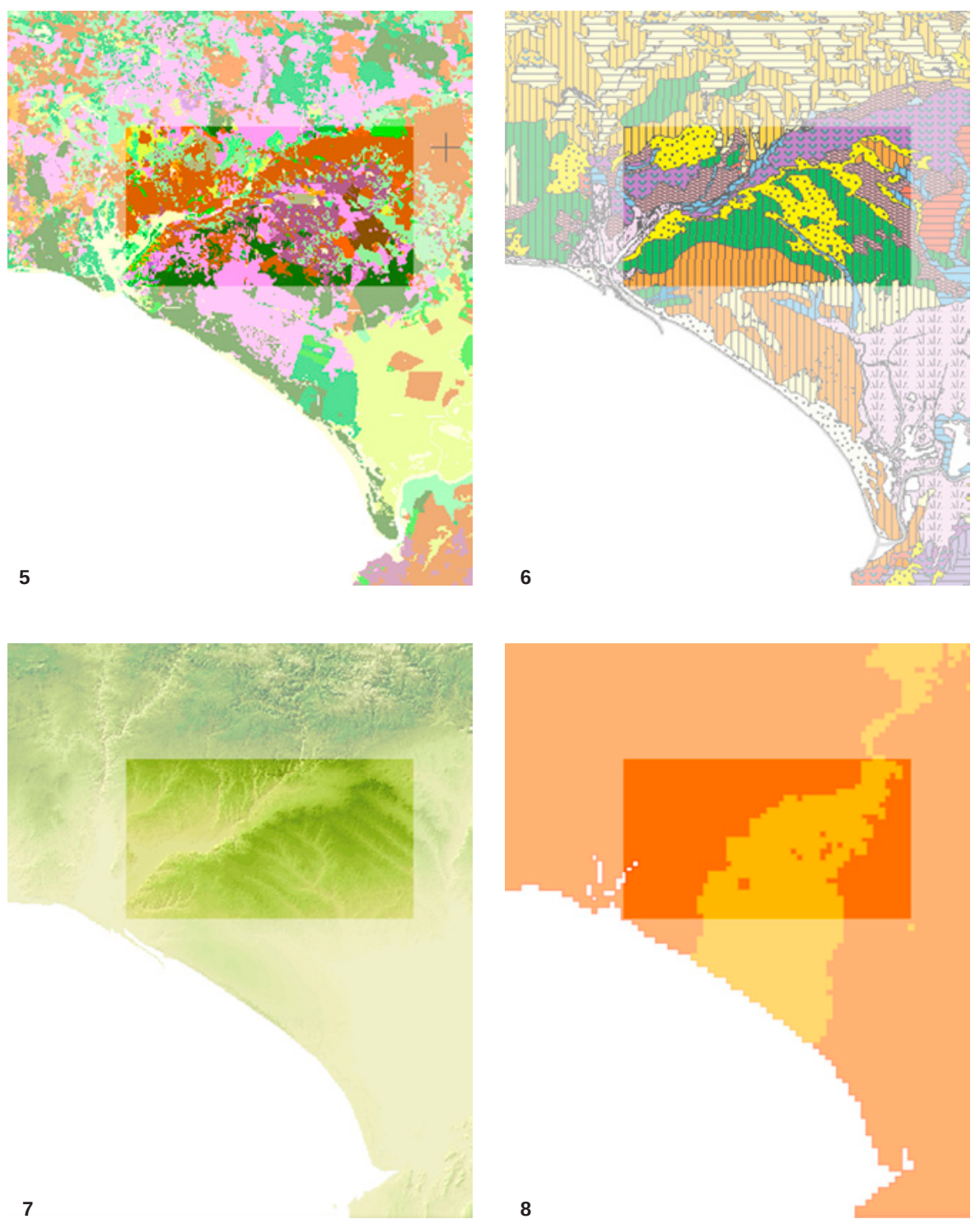

Este relieve suavemente inclinado hacia el océano aporta unas características únicas de aireación y temperatura diferenciada, generando una climatología propia para el Condado. De este modo, la brisa marina que penetra desde el Atlántico en Doñana no se interrumpe y alcanza, kilómetros adentro, hasta el final de este borde vitícola elevado, quedando así contenida y estabilizada. Este relieve condal limítrofe, junto con la vegetación y el sistema de marismas presentes en el Parque, permiten la generación de un microclima con una temperatura media anual más templada que en las zonas contiguas (SISTEMA), algo muy favorable para la actividad vitivinícola.
5. Mapa de cultivos del Condado. Viñedo en secano (morado) y asociación de viñedo y olivar (verde oliva)

6. Mapa de suelos propios del Condado. Limos basales semipermeable-permeable (amarillo)

7. Relieve inclinado hacia el Atlántico del Condado

8. Gráfico de la temperatura media anual, más baja en el Condado vitivinícola (amarillo) que en el resto de Huelva (naranja)
Según el Pliego de condiciones Denominación de Origen Condado de Huelva (2011), esta climatología se caracteriza por: $22.5^{\circ} \mathrm{C}$ de temperatura máxima, $9.8-11.9^{\circ} \mathrm{C}$ de temperatura mínima, $15.8-16.9^{\circ} \mathrm{C}$ de temperatura media, 810-716 $\mathrm{mm}$ de régimen pluviométrico, 30003100 horas de sol efectivo como índice de insolación, y un 60-80 \% de humedad relativa. 
10

Además de la figura administrativa de la mancomunidad, existen los partidos judiciales, que organizan el territorio agrupando varios municipios. Sin embargo, aquí parece primar más la cercanía que la pertenencia al Condado.

11

Este estudio, que sigue la estela del Convenio Europeo del Paisaje de 2000, es pionero al recoger por primera vez el mapa andaluz distinguiendo entre sus diferentes paisajes, sentando de este modo una base para la Estrategia de Paisaje de Andalucía de 2012.

\section{EL CONDADO EN LA ACTUALIDAD}

El concepto de comarca viene recogido en el Estatuto de Autonomía de Andalucía (2007: Art. 97) como la "agrupación voluntaria de municipios limítrofes con características geográficas, económicas, sociales e históricas afines", y no posee competencias administrativas, aunque en la práctica la figura de la mancomunidad suple esta carencia ${ }^{10}$. No obstante, ambas delimitaciones, comarca y mancomunidad, no tienen por qué coincidir, como sucede en el caso de la Comarca del Condado "de Huelva".

La demarcación actual del Condado no está del todo clara, como manifiesta la discrepancia entre los diferentes autores. A la falta de unidad histórica y geográfica se añaden figuras administrativas autónomas recientes, como el Parque Nacional de Doñana y el área metropolitana de Huelva, que superponen sus zonas de influencia sobre el territorio propio del Condado. Resulta más fiable, por tanto, una delimitación que atienda a aspectos concretos en lugar de una general y absoluta; tal es el caso del Condado del vino y de la vid.

La relevancia de Doñana (inscrita en la Lista del Patrimonio Mundial como Patrimonio Natural, 1994) establece una estrecha relación con el mundo agrario de su entorno (MANIFIESTO, 2011). Además, gran parte del territorio del Condado se encuentra directamente incluido en su zona de protección: "los municipios incluidos en el área socio-económica del Parque Nacional son: Almonte, Aznalcázar, Hinojos y Puebla del Río. Sin embargo, la Comarca de Doñana, territorio íntimamente relacionado con el Espacio Natural de Doñana, se compone de 14 municipios entre los que destacan, además de los citados: Bollullos Par del Condado, Bonares, Lucena del Puerto, Moguer, Palos de la Frontera y Rociana del Condado en Huelva, Isla Mayor, Pilas y Villamanrique de la Condesa en Sevilla y, finalmente, Sanlúcar de Barrameda en Cádiz" (CASTAÑO CORRAL; MATEOS MATEOS; RIVERA SILVA, 2010).

La diferenciación respecto a este espacio natural queda reflejada en la demarcación del Paisaje Cultural del Condado ${ }^{11}$ realizada por el IAPH (2010) desde un punto de vista cultural y patrimonial. Esta delimitación, aunque pone en valor sus características agrarias como conformadoras esenciales del paisaje, desde la perspectiva que nos ocupa, no reconoce la totalidad del sistema cultural asociado a la vitivinicultura del Condado.

En el otro extremo se encuentra la Denominación de Origen Condado de Huelva, que recoge ampliamente todos los términos municipales que participan en esta actividad, dando como resultado una delimitación administrativa muy extensa que no se corresponde verdaderamente con la cultura vitivinícola en el Condado. 

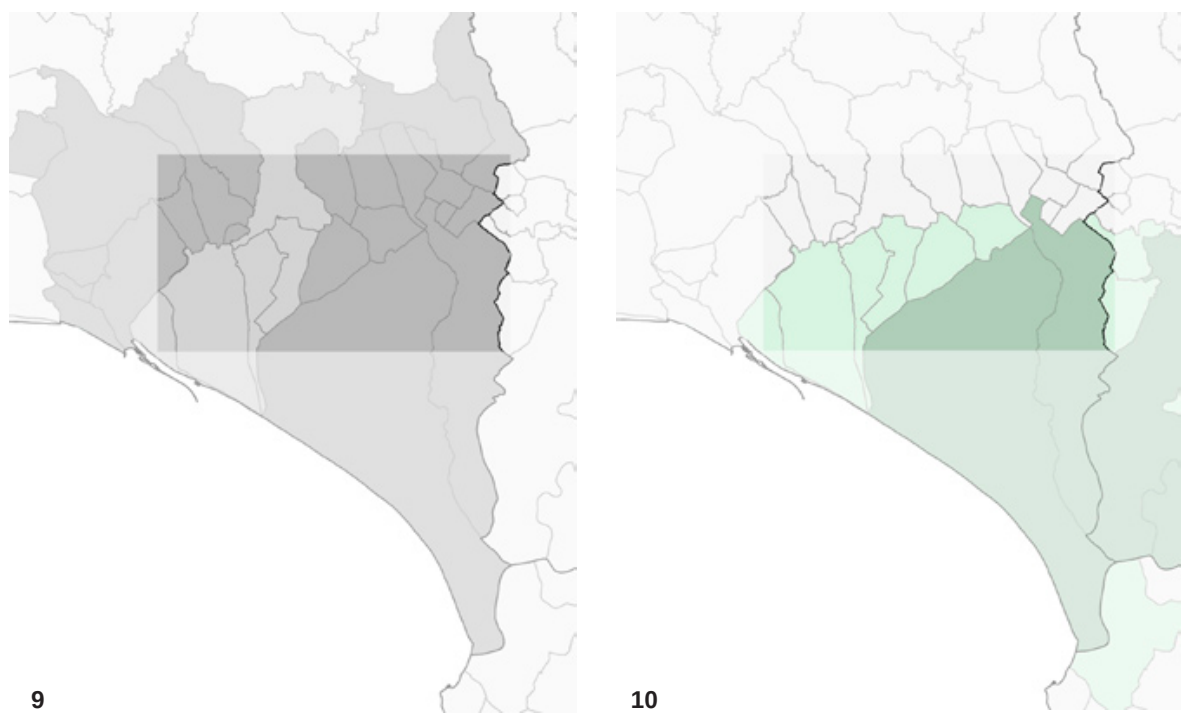

9. Partidos Judiciales de Huelva, Moguer y La Palma del Condado (respectivamente de izquierda a derecha)

10. Municipios que forman parte del Parque Nacional de Doñana (verde oscuro) y los incluidos en la Comarca de Doñana (verde claro)

11. Demarcación del Paisaje Cultural del Condado realizada por el IAPH (amarillo)

12. Municipios integrados en la Denominación de Origen Condado de Huelva. Municipios de cultivo (morado claro) y municipios de cultivo y crianza (morado oscuro)
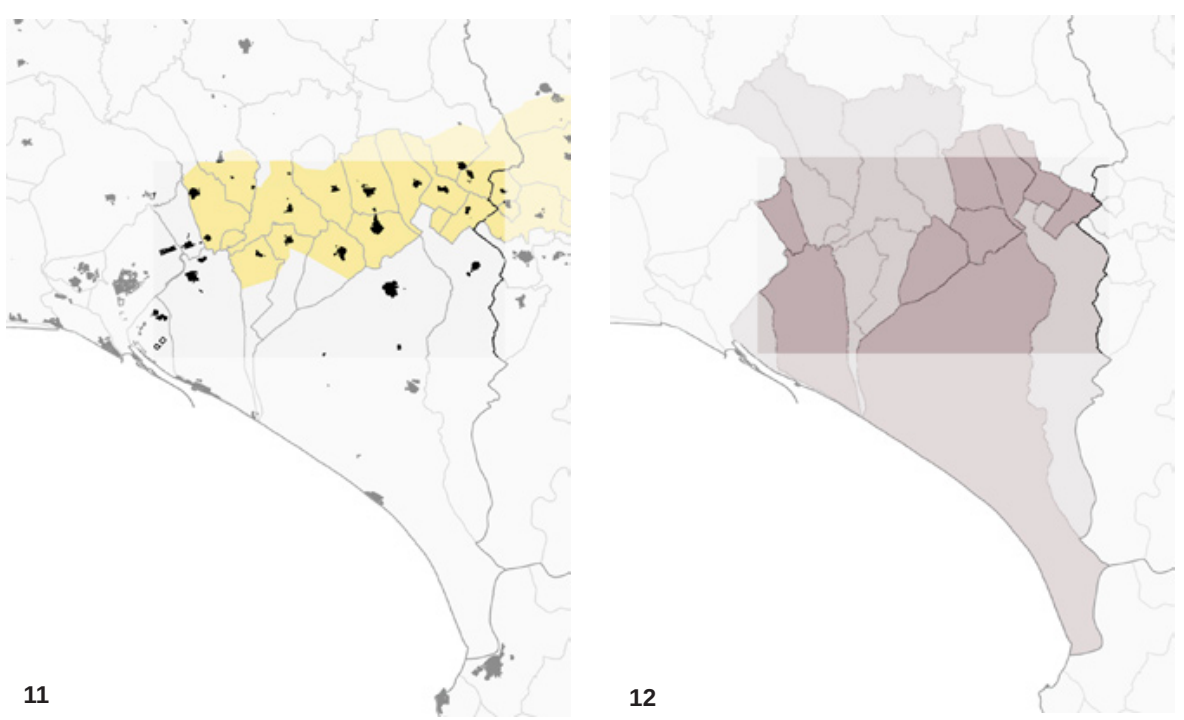

\section{EL CONDADO DEL VINO Y DE LA VID: DELIMITACIÓN PROPUESTA}

Para una correcta lectura del territorio es necesario encontrar el nivel apropiado de escala y de relaciones, pues lo mismo que una visión acotada resultaría una mirada sesgada, el caso contrario obtendría sistemas tan complejos que impediría la comprensión óptima de un paisaje cultural. La carestía de una delimitación adecuada para el Condado motiva la formulación de una propuesta en base a este aspecto concreto generador de identidad y que es suma de diferentes relaciones históricas y con el medio natural. Frente a las demarcaciones dispares señaladas anteriormente, los viñedos y su vin- 

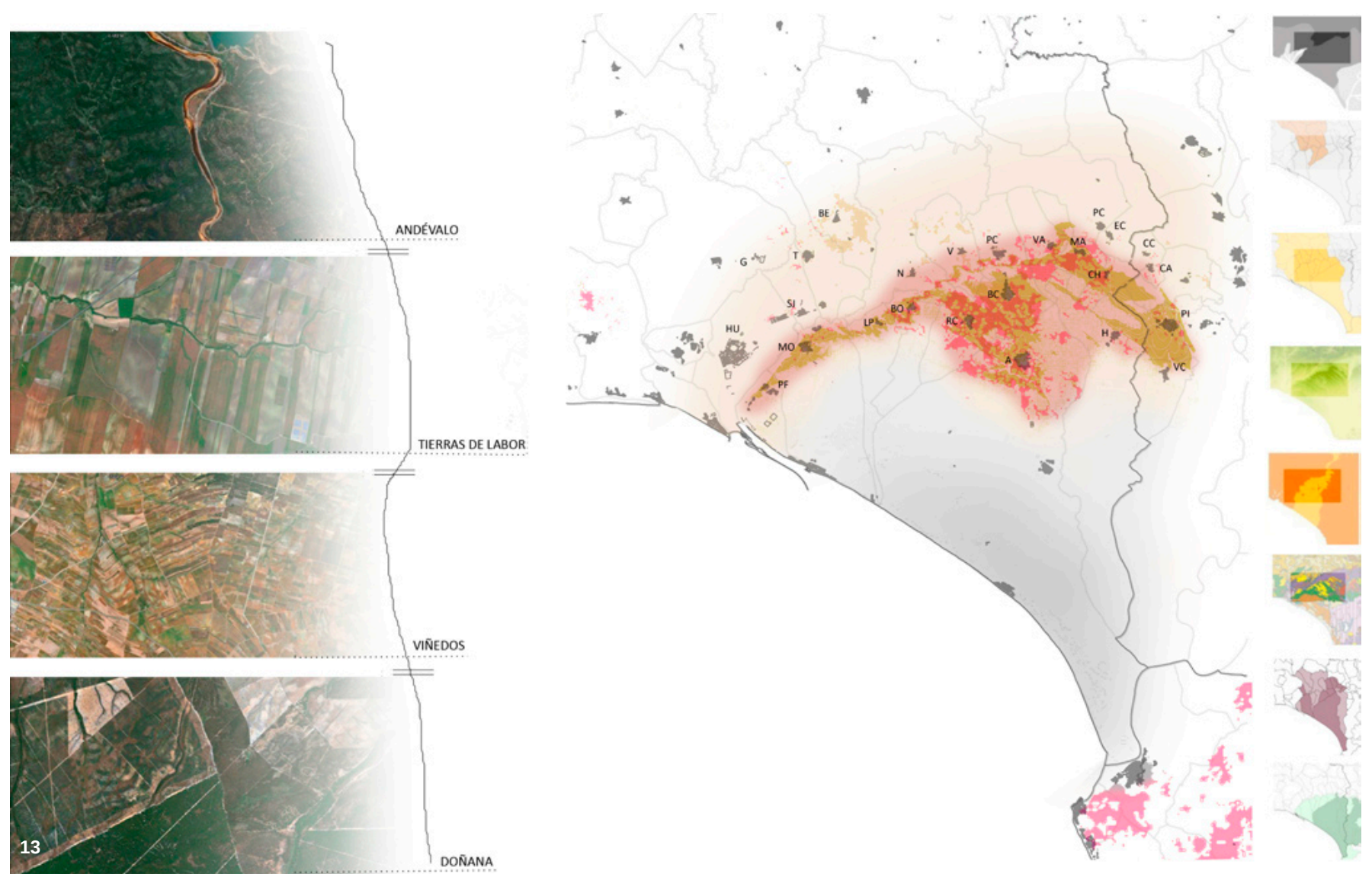

13. Delimitación para el Condado del vino y de la vid, resultado de diferentes aspectos territoriales. Viñedos y tierras vitícolas (rosa y ocre) y su continuidad con las tierras de labor (marrón claro) y Doñana (gris)

culación histórica aportan unidad a todo el Condado, siendo éste un criterio válido para definir y analizar su paisaje. Es posible, por tanto, hablar de la existencia de una unidad paisajística del viñedo en el Condado, que queda constatada a simple vista de pájaro y que aún no se ha plasmado convenientemente en ninguna figura, reconocimiento o estudio. El impreciso o controvertido concepto del Condado toma fuerza cuando se considera su antigua cultura vitivinícola, que verdaderamente ha mantenido a todos sus pueblos moviéndose al mismo compás a través de la historia. Tanto es así que, aunque no hay un absoluto consenso en la delimitación de esta comarca onubense, sí se puede hablar del vino y de la vid como fuente de identidad cultural para el conjunto de sus pueblos. La vitivinicultura del Condado no sólo significa la actividad económica más representativa del lugar, sino que hablar de vino aquí es hacer referencia a un completo modo de vida. Su histórica cultura de producción y crianza ha permanecido hasta nuestros días, lo que ha permitido generar una interesante huella evolutiva sobre el territorio. Desde sus primeras plantaciones de vid, realizadas unos cinco mil años atrás según la investigación de Stevenson (SÁEZ FERNÁNDEZ, 1995: 15) y 
otras excavaciones arqueológicas (ANUARIO, 2005: 1573), la tradición vitivinícola ha permanecido en el Condado como un hecho continuado a través del paso de las distintas civilizaciones romana, musulmana y cristiana. Ha sobrevivido a los diferentes estragos históricos y conseguido ser un elemento fundamental en la configuración de este lugar. De tal manera que la cultura del vino y la vid ha nutrido todas las facetas vitales del Condado, generando un conjunto patrimonial, tanto tangible como intangible, que acerca y establece lazos comunes entre sus pueblos. Se trata de los aspectos inmateriales asociados a la realización de esta actividad, así como aquellos derivados del desarrollo de la misma a lo largo de la historia y que han dado forma al territorio y cultura de este pueblo: arquitectura, urbanismo, saberes tradicionales, festejos, gastronomía, fuente de inspiración artística y otras manifestaciones culturales.

La delimitación que se propone aquí para el Condado del vino y de la vid asume la realidad compleja del lugar y no se restringe meramente a la acotación de los terrenos de viñedos, actuales e históricos, sino que intenta generar un mapa cultural completo para este rico patrimonio. Realmente una de las características del viñedo del Condado es su disposición en mosaico (MANIFIESTO, 2011), mediante pequeñas propiedades que se intercalan de manera diversa con otros cultivos tradicionales como el cereal y el olivar. Por ello, aunque el medio físico posibilita una radicalización de esta cultura vitivinícola en torno a los municipios de Bollullos Par del Condado, Rociana del Condado y Almonte, los pueblos del Condado han funcionado históricamente como sistema en la producción. Así entre Chucena y Palos de la Frontera, se conforma un friso de viñedos y bodegas interrelacionadas mediante el comercio y la propia elaboración, que continúa hasta nuestros días. Aspectos que refuerzan estos vínculos y da coherencia a toda esta comarca.

La complejidad y necesaria continuidad de un sistema medioambiental provoca que esta orla de viñedos quede estrechamente relacionada a su entorno. El inmediato ámbito de Doñana y las tierras de labor al norte conforman una prolongación indisoluble del paisaje vitivinícola del Condado, generando interrelaciones naturales y culturales que vertebran todo su territorio. El resultado finalmente obtenido en esta propuesta para el Condado del vino y de la vid es una acotación concreta pero a la vez difusa, que pretende integrar toda la región donde se identifican esos valores culturales y naturales.

Se puede afirmar justamente que el papel desempeñado por la vitivinicultura en el Condado es trascendental. Sin embargo, a pesar de ello, es necesario reivindicar un merecido reconocimiento hacia esta práctica agraria y su patrimonio asociado. Como se ha descrito, se trata de un elemento de cohesión territorial que brinda enormes posibilidades de desarrollo futuro para esta comunidad. Está en consonancia con la ética contemporánea de sostenibilidad y responsabilidad sobre los valores patrimoniales del lugar, permitiendo la continuidad de la cultura milenaria del Condado.

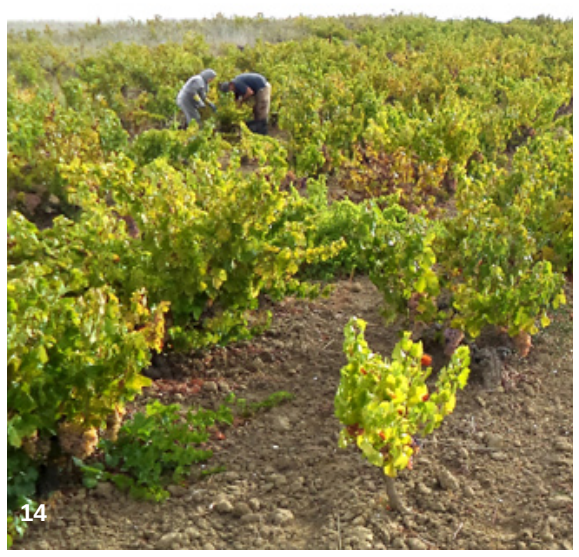

14. Vendimia en pequeño viñedo familiar plantado "en vaso" sobre tierras albarizas. Bollullos Par del Condado 


\section{BIBLIOGRAFÍA}

- AlAdro PRieto, J. M. (2012) La Construcción de la Ciudad Bodega. Arquitectura del Vino y Transformación Urbana en Jerez de la Frontera en el s. XIX [en línea]. Tesis doctoral, Universidad de Sevilla, $2012<$ <ttp:// fondosdigitales.us.es/tesis/autores/1943/> [Consulta: 15/01/2014]

- AMADOR DE LOS RÍOS Y FERNÁNDEZ DE VILLALTA, R. (1891) Huelva. Barcelona: Establecimiento Tipográfico "Arte y Letras", 1891

- ANUARIO arqueológico de Andalucía 2005 [en línea]. Junta de Andalucía: Consejería de Cultura, $2005<$ http:// www.juntadeandalucia.es/cultura/publico/BBCC/Anuario 2005/Huelva.pdf> [Consulta: 20/08/14]

- BIEDMA PÉREZ, L; CARRASCO TERRIZA, M. J.; CLEMENTE MARTíN, R. M. et ál. (2003) Patrimonio Histórico. Bollullos Par del Condado. Sevilla: Ayto. de Bollullos Par del Condado, 2003

- CARRASCO TERRIZA, M. J.; GÓNZALEZ GÓMEZ, J. M. (2009) Catálogo monumental de la provincia de Huelva. Huelva: Universidad de Huelva, 2009

- CASTAÑo CORRAL, A.; MATEOS MATEOS, J.; RIVERA SILVA, M. L. (2010) Guía de visita del Parque Nacional de Doñana [en línea]. Madrid: Organismo Autónomo Parques Nacionales, $2010<$ <ttp://www. magrama.gob.es/imagenes/es/Guia\%20Donana_tcm7292144.pdf> [Consulta: 10/02/2014]

- CASTIllo RUIZ, J. (dir.) (2013) Carta de Baeza sobre Patrimonio Agrario [en línea]. Sevilla: Universidad Internacional de Andalucía, 2013 <http://www. patrimonioagrario.es/pago/CARTA_DE_BAEZA_files/ carta.pdf> [Consulta: 01/04/2014]

- FERNÁNDEZ CACHO, S.; FERNÁNDEZ SALINAS, V.; HERNÁNDEZ LEÓN, E. et ál. (2010) Paisajes y patrimonio cultural en Andalucía. Tiempo, usos e imágenes. Sevilla: Instituto Andaluz del Patrimonio Histórico, Consejería de Cultura, 2010

- Fourneau, F. (1975) El Condado de Huelva: Bollullos Capital del Viñedo. Huelva: Instituto de Estudios Onubenses, 1975

- GARCía Flores, A. (1998) El Condado y sus vinos. Historia y presente. Narria: Estudios de artes y costumbres populares [en línea], n. ${ }^{\circ} 81-84,1998$, pp. 69-75 <https:// repositorio.uam.es/bitstream/handle/10486/8576/45934 6.pdf?sequence $=1>$ [Consulta: $26 / 04 / 2014$ ]

- HERNÁNDEZ PACHECO, F. (1961) Rasgos geográficos y geológicos del Estrecho de Gibraltar y de las comarcas que lo limitan [en línea]. Real Academia de Ciencias, 1961 <http://www.rac.es/ficheros/Revistas/REV_20100220_ 02554.pdf> [Consulta: 25/07/2014]
- LAdero QuesadA, M. (1992) Niebla, de Reino a Condado. Noticias sobre el Algarbe andaluz en la Baja Edad Media. Huelva: Diputación Provincial de Huelva, 1992

- LEY 14/2007, de 26 de noviembre, del Patrimonio Histórico de Andalucía. Boletín Oficial de la Junta de Andalucía, n. ${ }^{\circ}$ 248, de 19 de diciembre de 2007

- MADOZ IBÁÑEZ, P. (1846-50) Diccionario geográficoestadístico-histórico de Andalucía. Valladolid, 1988. Reprod. facs. parcial del Diccionario geográfico- estadístico-histórico de España y sus posesiones de Ultramar. Madrid: [s.n.], 1846-1850 (Establecimiento tipográfico de P. Madoz y L. Sagasti)

- MANifiesto: el viñedo tradicional en secano de Doñana. Signo de diversidad y paisaje vital (2011) [en línea]. Huelva: Fundación Doñana21, Consejería de Agricultura y Pesca, Consejería de Medio Ambiente et ál. <http://www.conozcadonana.com/arch_var/manifiesto vinedo_donana[1].pdf> [Consulta: 01/12/2014]

- MAPA de Suelos de Andalucía. 1:400.000 (2005) [en línea]. Consejería de Medio Ambiente <http://www. juntadeandalucia.es/medioambiente/site/rediam> [Consulta: 05/03/2014]

- MARTÍNEZ YÁÑEZ, C. (2010) The International Day for Monuments and Sites. Theme for 2010: "The Heritage of Agriculture". ICOMOS International Secretariat e-news [en línea], n. ${ }^{\circ}$ 54, 2010 Special Issue International Day for Monuments and Sites 18 April 2010: The Heritage of Agriculture <http://www.icomos.org/18thapril/2010/18 April_2010_Agricultural\%20Heritage_Eng_20100323.pdf> [Consulta: $26 / 10 / 2014]$

- MORENo NAVARRo, I. (1995) La cultura del vino en Andalucía: identidades socioculturales y culturas de trabajo. En IGLESIAS RODRÍGUEZ, J. J. (coord.) Historia y cultura del vino en Andalucía. Sevilla: Universidad, 1995, pp. $179-200$

- PÉRez CANo, M. T. (1997) el Sistema de los Conventos de Clausura en el Centro Histórico de Sevilla: Génesis, Diagnóstico y Propuesta de Intervención para su Recuperación Urbanística. Sevilla: Universidad de Sevilla, Secretariado de Publicaciones, Fundación Fondo de Cultura de Sevilla, 1997

- PLIEGO de condiciones de la Denominación de Origen "Condado de Huelva" (2011) [en línea]. Sevilla: Consejería de Agricultura, Pesca y Desarrollo rural, $2011<$ http://www. juntadeandalucia.es/agriculturaypesca/portal/export/sites/ default/comun/galerias/galeriaDescargas/cap/industriasagroalimentarias/denominacion-de-origen/vinos/V_DO_ CONDADO_DE_HUELVA.pdf> [Consulta: 09/04/2014]

- ROLDÁN CASTRO, F. (1993) Ibn Mahfuz en Niebla (siglo VII/XIII). Anaquel de Estudios Árabes [en línea], 
IV, 1993 pp. 161-177 <http://dialnet.unirioja.es/servlet/ articulo?codigo=151768> [Consulta: 5/03/2014]

- SÁEZ FERNÁNDEZ, P. (1995) El vino en la Bética romana. En IGLESIAS RODRÍGUEZ, J. J. (dir.) Historia y Cultura del Vino en Andalucía: Conferencias del Seminario "Historia y Cultura Del Vino En Andalucía". Sevilla: Universidad de Sevilla, Secretariado de Publicaciones, 1995, pp. 13-32

- SISTEMA de Información Geográfica de Datos Agrarios (SIGA) [en línea]. Madrid: Ministerio de Agricultura, Alimentación y Medio Ambiente <http://sig.marm.es/siga/> [Consulta: 20/01/2014]

- STEVENSON, A. C. (1985) Studies in vegetational history of SW. Spain. II. Palinological investigation at Laguna de las Madres, S. W. Spain. Journal of Biogeography, vol. 12, 1985, pp. 293-314

- La VITIVINICULTURA del Condado de Huelva: I Jornadas técnicas de la vid y del vino Condado de Huelva (1982) Huelva: Junta de Andalucía. Consejería de Agricultura y Pesca, 1982 